\title{
SOPHIE CALLE \& PAUL AUSTER: DOUBLES-JEUX
}

\section{SOPHIE CALLE \& PAUL AUSTER: DOUBLES-JEUX}

ISABEL BARAONA ${ }^{1}$ 


\section{Resumo}

Apresentação de Doubles-jeux, um conjunto de 7 (sete) livros de artista de Sophie Calle feitos a partir de uma colaboração com o romancista americano Paul Auster. O texto foi redigido em português europeu.

Palavras-chave: Livros de artista. Autobiography. Ficction.

\section{Abstract}

An introduction to Doubles-jeux, a set of 7 artists' books by Sophie Calle, done in collaboration with American novelist Paul Auster. This text was written in European Portuguese.

Keywords: Artists' books. Performance. Performance. Autobiografia. Ficção.

ISSN: 2175-2346 
Sophie Calle é uma artista francesa que há vários anos nos conta histórias verdadeiras ${ }^{1}$. Persevera de forma sistemática na recolha de pequenos acontecimentos do dia-a-dia, actua como uma investigadora de tudo que preenche o seu quotidiano, o que circunda a sua vida.

Doubles-jeux é um projecto exemplar da forma como Calle transforma episódios triviais num momento seminal, gerador de uma elaborada construção narrativa que comummente, e para além da própria artista, implica outros intervenientes, seja uma participação voluntária ou não. Doubles-jeux é fruto de um encontro entre Sophie Calle e Paul Auster, tomando a forma de uma colecção de 7 livros intitulados: De l'obéissance (Livro I); Le rituel 'anniversaire (Livro II); Les panoplies (Livro III); A suivre... (Livro IV); L'hôtel (Livro V); Le carnet d'adresses (Livro VI); Gotham Handbook (Livro VII) $)^{2}$.

Doubles-jeux foi construído, não em diálogo mas, em resposta ao enredo de Léviathan ${ }^{3}$, livro editado por Paul Auster em 1992 cujo enredo se desenrola em New York. Calle serve de inspiração para Maria Turner, personagem criada por Auster em Léviathan. Sophie Calle/Maria Turner é descrita como sendo

\begin{abstract}
(...) uma artista, mas a sua obra não tinha nada a ver com a criação de objectos comummente definidos como arte. Algumas pessoas consideravam-na uma fotógrafa, outras uma conceptualista, outras ainda uma escritora, mas nenhuma destas descrições era exacta, e, vendo bem, não creio que possamos encaixá-la em nenhuma das categorias existentes. O seu trabalho era demasiado louco, demasiado idiossincrático, demasiado pessoal, e, por isso, não poderia ser encarado como pertencendo a um médium ou disciplina particulares. Deixava que as ideias se apossassem dela, desenvolvia projectos, havia resultados concretos que podiam ser exibidos em galerias, mas esta actividade decorria menos de um desejo de fazer arte do que de uma necessidade de consumar as suas obsessões, de viver a sua vida exactamente como queria (AUSTER, 2003, pp. 70-71). Tradução nossa.
\end{abstract}

Se a descrição acima pode ser considerada fiel à pessoa de Calle, no que respeita a descrição física da personagem apenas um detalhe é verdadeiro, os olhos com uma peculiar cor cinzenta. Maria Turner é caracterizada como sendo uma mulher alta, com cabelo curto e loiro ${ }^{4}$, o que em nada se assemelha a Calle.

Nas páginas 4 e 5 de De l'obéissance (Livro l) Calle esclarece o que denomina "as regras do jogo" 5 . Nas páginas seguintes, nas margens do bloco de texto que reproduz fragmentos do romance de Auster, aparecem - sublinhados a cor-de-rosa - as diferenças entre o enredo criado pelo autor americano e factos da vida-obra de Calle, com anotações e correcções. A leitura de De l'obéissance exige grande atenção aos detalhes, por exemplo: a numeração das páginas 10-19 é alterada e corresponde à

\footnotetext{
1 Título de um dos seus livros de artista publicado em colaboração com Actes-Sud.

2 Títulos estes que em português poderiam ser traduzidos livremente como Da obediência, 0 ritual de aniversário, As roupas, $A$ seguir..., $O$ hotel, $A$ agenda de endereços, Manual de Gotham.

3 Edição original: AUSTER, P. - Leviathan. N.Y., Viking Penguin Inc., 1992.

4 Edição portuguesa: AUSTER, P. - Leviathan. Lisboa, ASA, 2003. Página 69.

5 "Il s'est en effet servi de certains épisodes de ma vie pour créer, entre les pages 84 et 93 de son récit, un personnage de fiction prénommé Maria (...) Séduite par ce double, j'ai décidé de jour avec le roman de Paul Auster et de mêler, à mon tour et à ma façon, réalité et fiction". In, CALLE, S. - De l'obéissance (Livro I). Paris, Actes Sud, 2002.
} 
edição original fac-similada de Leviathan ou seja, 84-93. Na página 6, Calle assinala a cor-de-rosa a dedicatória do seu livro: "A autora agradece especialmente a Paul Auster por a ter permitido misturar ficção com realidade"6. Na página 7, usando a mesma estratégia, assinala a página fac-similada de Leviathan com a menção: "O autor agradece especialmente a Sophie Calle por o ter permitido misturar ficção com realidade"7.

Através de uma indicação subtilmente inserida no bloco de texto, Calle distingue cada um dos 7 volumes aos quais correspondem projectos artísticos específicos ou seja, cada livro trata um conjunto de acções ou performances:

De l'obéissance (Livro I): Calle encena com grande rigor os dois rituais criados por Auster para Maria Turner: o regime alimentar cromático e estruturar um dia inteiro a partir de certas letras do alfabeto, ambos os rituais têm a duração de uma semana.

Le rituel 'anniversaire (Livro II): entre 1980 e 1993, na data do seu aniversário, Sophie Calle convidou o número de pessoas equivalente ao número de anos que celebrava, entre os quais um desconhecido. Fotografou todos os presentes dispostos numa vitrina, excepção feita a uma geladeira (representada pelo livro de instruções e que foi utilizada).

Les panoplies (Livro III) narra duas acções: em Dezembro de 1985 Calle conhece um homem que a agrada e a quem começa a oferecer, anonimamente e regularmente até 1993, roupa (gravatas, calças, camisas, etc). Aos 26 anos disfarçada com uma peruca loira, Calle decide fazer e documentar o seu striptease numa barraca de feira na praça Pigalle, a acção acabou quando outra dançarina quebrou a sua cabeça com o salto agulha de um sapato alto.

A suivre (Livro IV) está dividido em Preambulo, Suite Vénitienne, La filature. No preambulo Calle explica que durante meses seguia na rua pessoas desconhecidas, fotografando-as até perdê-las de vista. Por mero acaso, um dos desconhecidos que Calle havia seguido durante o dia, posteriormente nomeado como Henri B., foi-lhe apresentado numa recepção. Suite Vénitienne narra a experiência de ter seguido Henri B. até Veneza. La filature é uma acção de 1981 que consiste em, com a ajuda da mãe, contratar um detective privado para seguir Calle. Este livro tem uma dedicatória muito pessoal: Ao meu pai, Robert Calle, que me encorajou a seguir e à minha mãe, Rachel Sindler, que me fez ser seguida. ${ }^{8}$

L'hôtel (Livro V): em 1981, Calle faz-se contratar como empregada de limpeza num hotel em Veneza. Enquanto limpava os quartos observava os objectos dos hospedes viajantes, documentando o retrato que deles ia fazendo a partir de pequenos indícios.

Le carnet d'adresses (Livro VI): Em 1983 Calle encontra uma caderneta de endereços na rua. Fotocopia-a antes de a devolver - por correio e anonimamente - ao seu dono. Um jornal de circulação nacional havia-a contratado para escrever um folhetim (publicado em capítulos) e Calle decide telefonar a alguns dos nomes que constavam na agenda para que lhe descrevessem o seu proprietário, apesar dela pró-

\footnotetext{
$6 \quad$ No original: "L'auteur remercie tout spécialmente Paul Auster de l'avoir autorisée à mêler la fiction à la reálité."

7 No original: "L'auteur remercie tout spécialmente Sophie Calle de l'avoir autorisée à mêler la fiction à la reálité."

8 À mon père, Robert Calle, qui m'a encouragée à suivre et à ma mère, Rachel Sindler, qui m'a fait suivre.
} 
pria o conhecer. O projecto foi objecto de grande controvérsia em França pois, após a sua apresentação/divulgação, o verdadeiro dono da agenda - o documentarista e realizador Pierre Baudry - a acusou publicamente de invasão de privacidade, processando-a.

Gotham Handbook, o sétimo e último volume desta colecção, difere do restante conjunto e é construído com o seguinte desígnio: Calle pede a Auster para criar uma personagem de ficção que iria personificar. Nas suas palavras ofereci a Paul Auster a oportunidade de fazer de mim o que quisesse ${ }^{9}$. Contudo Auster declina essa proposta: "Ele objectou que não desejaria assumir a responsabilidade do que poderia acontecer quando obedecesse ao enredo para mim criado. Ele preferiu enviar-me Instruções personalizadas para Sophie Calle afim de melhorar a sua vida em Nova York (porque ela mo pediu...). ${ }^{10}$ Tradução nossa.

Gotham Handbook é então o resultado da implementação dessas instruções e assim, por um curto lapso de tempo, Auster é parcialmente o autor dos actos de Calle. E o que sugere Auster? Nada mais do que sorrir a desconhecidos; falar com desconhecidos, conversando sobre o tempo ou elogiando algo que vestem; dar comida e cigarros a mendigos dando-lhes tempo e atenção; adoptar um lugar e torná-lo seu limpando-o e embelezando-o.

Em suma, há três tipos de performances ou acções: as acções já executadas por Sophie Calle, enquanto artista, que a personagem Maria Turner interpreta; as acções que Auster inventou para Maria Turner e que Sophie Calle vai interpretar como suas; e, o conjunto de instruções que Auster propõe a Calle executar durante a sua estadia em N.Y. Este esbater de fronteiras entre a elaboração da trama ficcional do escritor e a obra da artista é, para mim, um dos aspectos mais fascinantes do trabalho que Calle tem vindo a desenvolver nas últimas décadas.

O complexo plano remissivo tecido entre uma obra e outra parece ser portador de sentido para ambos os autores. Contudo, enquanto Leviathan é uma peça literária finalizada em 1992, Doubles-jeux desenvolveu-se durante 6 anos consecutivos e representa todo um manancial de experiências recolhidas por Calle radicalizadas na (quase) dissolução entre ficção e identidade, realidade e da dupla-autoria. Aspectos que se vão tornar fundamentais e estruturantes da obra da artista pois, durante 0 período de desenvolvimento e documentação de Gotham Handbook, a ficção sobrepôs-se à realidade do dia-a-dia; ou seja, Calle substituiu a sua vida privada e quotidiana pelo ritual performativo imposto pelo projecto.

Posteriormente, em Où et quand, colaborou com a vidente Maud Kristen a quem pede para predizer o futuro e, após ler as cartas de tarot, responder "onde" e "quando" esse futuro terá lugar "afim de ir ao seu encontro, de o apreender rapidamente"11. Em Où et Quand? Lourdes a artista afirma que não tem interesse em confirmar o dom de vidência de Kristen mas quer deixar-se manipular, ir para um futuro que não imagi-

9 In, CALLE, S. - De l'obéissance (Livro I). Paris, Actes Sud, 2002.

10 II objecta qu'il ne souhaitait pas assumer la responsabilité de ce qui pourrait advenir alors que j'obéirais au scénario qu'il avait crée pour moi. II a préféré m'envoyer des Instructions personnelles pour Sophie Calle afin d'améliorer la vie à New York (parce qu'elle me l'a demandé...) CALLE, S. - De l'obéissance (Livro I). Paris, Actes Sud, 2002. Página 5

11 afin d'aller à sa rencontre, de le prendre de vitesse. In, CALLE, S. - Où et Quand? Berck. Paris, Actes Sud, Setembro 2008. Página 83. CALLE, S. Où et Quand? Lourdes. Paris, Actes Sud, Abril 2009. Página 9. 
nou, abandonar-se, renunciar ${ }^{12}$. Maude Kristen recusa-se a isso afirmando que o livre arbítrio de Calle é essencial para que possa interpretar livremente e a través do trabalho artístico, as pistas dadas pelo seu conhecimento das artes divinatórias ${ }^{13}$. Existe um claro paralelo com Gotham Handbook, pois Calle pede que a vidente lhe dê ordens ${ }^{14}$ sobre onde ir e o que fazer quando chegar ao destino.

Para concluir, a obra multifacetada e pluridisciplinar de Sophie Calle, que inclui instalações, acções e performances (e respectiva documentação), livros de artista, séries de fotografias, vídeos, etc. constrói-se a partir da sua experiência emocional enquanto indivíduo. Os pequenos acontecimentos do quotidiano, o amor ou o sentimento amoroso, a perda e a morte, a desilusão, são experiências passíveis de activar mecanismos de identificação, e que podem ser partilhadas por toda e qualquer pessoa a dada etapa da vida. Mas, a obra exposta e editada nos livros é indiscutivelmente um corpo de trabalho, um complexo projecto artístico que, embora entretecido com a vida, lhe é extrínseco ancorando-se no território da arte. É interessante notar que a circulação dos seus livros ultrapassa as fronteiras do meio institucional e galerístico. No caso de Sophie Calle os livros de artista são objectos acessíveis, tanto ao público- leitor iniciado na arte contemporânea assim como a qualquer frequentador de livrarias e bibliotecas. E é, para mim, essa a beleza e excepcionalidade do seu projecto de livros de artista, serem uma obra de arte complexa, mas acessível, de problemática classificação mas integrada na esfera banal do quotidiano.

\section{Referências bibliográficas}

AUSTER, P. - Leviathan. N.Y: Viking Penguin Inc., 1992.

CALLE, S. - Doubles-Jeux - 7 volumes. Paris: Actes Sud, 2002.

CALLE, S. - Où et Quand? Berck. Paris: Actes Sud, Setembro 2008.

12 (...) Ce jeu n'est pas destiné à confirmer ou à démentir les dons de voyance de Maude Kristen. Je veux me laisser manipuler, téléguider. Aller vers un avenir que je n'ai pas imaginé et, même si Maude refuse de me donner des ordres, devenir la femme-objet de mon destin à travers ses visions. In, CALLE, S. - Où et Quand? Lourdes. Paris, Actes Sud, Abril 2009. Página 11.

13 CALLE, Sophie - Où et Quand? Berck. Paris, Actes Sud, Setembro 2008. Página 83.

14 termo usado por Calle: Elle refusait de me donner des ordres. in, CALLE, S. - Où et Quand? Berck. Paris, Actes Sud, Setembro 2008. Página 83. 